(A49) Disaster Content Varies in Australian Postgraduate Tertiary Emergency Nursing Courses: Implications for Educational Preparedness

J. Ranse, ${ }^{1}$ P. Arbon,${ }^{2}$ R. Shaban, ${ }^{3}$ J. Considine, ${ }^{4}$

B. Mitchell, ${ }^{4}$ S. Lenson ${ }^{5}$

1. Faculty of Health, Canberra, Australia

2. Adelaide, Australia

3. Brisbane, Australia

4. Melbourne, Australia

5. Canberra, Australia

Emergency nurses have key roles in responding to healthcare disasters. Emergency nurses often complete postgraduate qualifications in their area of specialty to equip them with a breadth and depth of knowledge to respond to the challenges and complexities of emergency nursing care. However, little is known about the disaster preparedness of emergency nurses in Australia. More specifically, the educational preparedness and training for disaster nursing roles is not well understood. This purpose of this study is to describe the disaster content of Australian postgraduate tertiary emergency nursing courses as a means of better understanding emergency nurses' educational preparedness for disaster. An exploratory, descriptive approach was used to survey postgraduate tertiary emergency nursing course convenors. Data were collected from course convenors by structured telephone interview. Questions included: (1) nursing background; (2) demographics and disaster experience of course convenors; (3) course type, duration and mode of delivery; and (4) the type and amount of disaster content. Currently, 12 universities in Australia offer postgraduate courses specific to Emergency Nursing, ranging from Graduate Certificates to Masters Degree level. Of these universities, 10 participated in this research project. This presentation will report on the demographics of course convenors, including their disaster education and experience. However, the focus of the presentation will be on the review of the course content. Seven courses had some disaster content, while three had none. The disaster content in these courses varied in both content and duration. Three had learning objectives, and one had an assessment item related to disasters. Five had recent modifications relating to disaster content; this was in response to real-world events, such as terrorism and communicable diseases. This research highlights that the disaster content in Australian postgraduate emergency nursing courses varies. This finding supports the need for national consistency and supporting framework for disaster content in post-graduate courses. The 2009 Ben Morley Scholarship, a financial award sponsored by the College of Emergency Nursing Australasia, supported this research.

Prehosp Disaster Med 2011;26(Suppl. 1):s15

doi:10.1017/S1049023X11000616

\section{(A50) The Nurse as Incident Commander}

D.J. Persell

School of Nursing, State University, United States of America

The year 2010 brought an unprecedented public health response to the novel H1N1 influenza pandemic. Included in that response were colleges and universities across the globe. At universities not associated with medical centers, medical directors of student health looked to nursing faculty or nurse practitioner directors of student health for leadership. From the day novel H1N1 was formally declared a public health emergency, Arkansas State University utilized a nurse faculty member with expertise in homeland security as its Incident Commander. A portion of the nurse's time was dedicated to managing the incident. The nurse was positioned to provide guidance and lead the response with an understanding of university structures as well as business and academic continuity. From the beginning, the nurse utilized the Incident Command System to manage the response. Portions of the University's Incident Command structure were activated and Incident Command meetings were held no less than every two weeks. A tabletop exercise was developed specifically for a university setting and to give University officials practice at pandemic management. The nurse's clinical focus and pre-established relationships with disaster response and public health officials allowed critical access to important resources that the University would have otherwise gone without. She guided the University through redefining their pandemic plan, including assisting residence life in establishing alternative housing for sick students. An on-line reporting system was developed that was utilized by faculty, students, staff, and other concerned constituents. A public awareness campaign on the campus was instituted and 1,000 posters were posted around campus encouraging sick students to stay home and/ or seek medical care. The World Health Organization, (US) Centers for Disease Control and Prevention, and Department of Education guidelines were monitored and implemented. Two mass-immunization clinics were held on the campus with $>$ 7,000 immunizations provided.

Prehosp Disaster Med 2011;26(Suppl. 1):s15 doi:10.1017/S1049023X11000628

(A51) Facilitating Disaster Nursing Research in Oceania Region V.M. Plummer, ${ }^{1}$ T. Telepo, ${ }^{2}$ S. Suryanto ${ }^{3}$

1. Medicine, Nursing and Health Sciences, Frankston, Australia

2. Medicine and Health Sciences, Port Moresby, Papua New Guinea

3. Faculty of Medicine, Malang, Indonesia

"Facilitating disaster nursing research in Oceania Region" Natural disasters in the Oceania region and surrounds include for example earthquakes, volcanic eruptions (Rabaul, PNG, 1994, Merapi, Indonesia 2006), tsunamis, floods,(Indian Ocean 2004) fires, drought (Australia, 2009) and also pest plaques and pandemics which affected the broader international community. Between 1980 and 2008, there were 380 disaster events reported in the Oceania region in which 4,450 people died. That is approximately 154 deaths and 668,786 people affected at a cost of approximately $\$$ US 889 million per year. However despite this significant number of deaths and injuries, there is limited reporting on the nursing experience during such disasters or the impact of nursing on communities during response and recovery. This is due to the prioritised clinical focus of nursing resources of most countries during these events. A network of authors and researchers is being established in the area to support the reporting of nursing research 